\title{
Economic Constraints - the Growing Challenge for Western Breast Cancer Centers
}

\author{
Rene P. Seidel ${ }^{a} \quad$ Michael P. Lux $^{b} \quad J$ Josef Hoellthaler ${ }^{a}$ Matthias W. Beckmann ${ }^{b}$ Wieland Voigt \\ a Siemens AG, Healthcare Sector, Customer Solutions Division, H CX CRM-VA HCC ONC, \\ bUniversity Breast Centre Franconia, University Hospital Erlangen, Friedrich Alexander University, Erlangen, Germany
}

\section{Keywords}

Breast Cancer Center - Expenditures and costs .

Process management · Process quality · Process efficiency · Health economics · Patient satisfaction · Clinical workflow $\cdot$ Breast cancer

\section{Summary}

Breast cancer care in Western countries has reached a considerable level of quality and standardization, which has contributed to the decline in breast cancer mortality. Certified Breast Cancer Centers (BCC) represent an important element of this development. Related to changes in reimbursement and growing costs, BCC face economic constraints which ultimately could endanger the achievements of the past. Thus, BCC have to optimize their care strategies from an economic perspective, particularly by increasing efficiency but also by adapting their service portfolio. This could result in competitive advantages and additional revenue by increasing case numbers and extra charges to patients. Furthermore, an intensification of collaboration with the outpatient sector resulting in an integrated and managed 'trans-sectoral' care approach which could allow to shift unprofitable procedures to the outpatient sector - in the sense of a win-win situation for both sectors and without loss of care quality - seems reasonable. Structured and specialized consulting approaches can further be a lever to fulfill economic requirements in order to avoid cuts in medical care quality for the sake of a balanced budget. In this review, economic constraints of BCC with a focus on the German healthcare system and potential approaches to ameliorate these financial burdens are being discussed.

\author{
Schlüsselwörter \\ Brustkrebszentrum - Aufwendungen und Kosten . \\ Prozessmanagement - Prozessqualität - Prozesseffizienz . \\ Gesundheitsökonomie · Patientenzufriedenheit . \\ Klinische Prozesspfade · Brustkrebs
}

\section{Zusammenfassung}

Die Behandlung des Brustkrebs hat in den westlichen Industrienationen ein erhebliches $\mathrm{Ma} ß$ an Qualität und Standardisierung erreicht, welches unter anderem auch zur Senkung der brustkrebsbedingten Mortalität beigetragen hat. Ein wichtiges Element für diese Entwicklung stellen zertifizierte Brustkrebszentren dar. Änderungen in der Behandlungsvergütung und steigende Gesamtkosten haben zu ökonomischen Einschränkungen für die Brustkrebszentren geführt, die letztlich die erzielten Fortschritte der vergangenen Jahre gefährden könnten. Als Antwort auf diese Engpässe müssen Brustkrebszentren ihre Behandlungspfade unter ökonomischen Gesichtspunkten verbessern. Dies kann insbesondere durch Steigerung der Effizienz aber auch Anpassung des Angebots-Portfolios erfolgen. Letztlich kann dies zu einem Wettbewerbsvorteil des Zentrums führen und zusätzliche Einnahmen durch gesteigerte Fallzahlen sowie zusätzliche Zahlungen von Patientinnen für Extraleistungen bewirken. Des Weiteren kann eine intensivierte Kooperation mit dem ambulanten Sektor im Sinne eines integrierten und gesteuerten "transsektoralen" Ansatzes genutzt werden, um unprofitable Prozeduren vom Zentrum in den ambulanten Sektor zu verlagern. Dies könnte bei geeigneter Steuerung ohne Verluste an Versorgungsqualität zu einer Win-Win-Situation für beide Sektoren werden. Strukturierte und spezialisierte Beratungsansätze können zusätzlich helfen, die ökonomischen Erfordernisse zu erfüllen, um einen Abbau medizinischer Versorgungsqualität zur Kostenreduktion zu vermeiden. In diesem Review werden die ökonomischen Engstellen von Brustkrebszentren mit Fokus auf Deutschland dargestellt und Ansätze zur Verbesserung der finanziellen Lasten diskutiert.

\section{KARGER \\ Fax +497614520714 \\ Information@Karger.com}

www.karger.com (c) 2013 S. Karger GmbH, Freiburg

$1661-3791 / 13 / 0081-0041 \$ 38.00 / 0$

Accessible online at:

www.karger.com/brc
Wieland Voigt, MD Associate Professor

Siemens AG

Healthcare Sector

Customer Solutions Division H CX CRM-VA HCC ONC

Allee am Röthelheimpark 3A, 91052 Erlangen, Germany

Wieland.voigt@siemens.com 


\section{Introduction}

Considering the complete range of cancer diagnoses from $\mathrm{C} 00$ to $\mathrm{C} 97$ according to the current ICD-10 classification, cancer accounted for nearly 1.5 million cases that received inpatient care in Germany in the year 2010. Of these 1.5 million cancer patients, about every 10th was suffering from breast cancer (ICD-10 C50) [1]. Expenses in Germany for breast cancer care were approximately $€ 1.97$ billion in 2008 , that is about $0.8 \%$ of Germany's total health expenditure of $€ 254.28$ billion per year referring to the Federal Statistical Office [1]. As a result of the aging population with a concomitant increase in chronic diseases such as cancer, both total health spending and cancer care expenses in particular are rising constantly every year [2]. Beside epidemiological factors, advances in medical diagnostics and treatments are further driving the rise of healthcare spending. As a consequence, this creates a growing burden for healthcare providers and payers in the healthcare system, and may bring them close to financial collapse. However, from the medical perspective, high-quality healthcare must be guaranteed against the background of financial pressure since cuts in healthcare spending will in the long run negatively impact on the individual patient outcome and hamper medical advancement. In this challenging situation, new strategies have to be developed in order to increase the efficiency of medical processes to stabilize cost development and thereby avoid cuts in the overall care offered to cancer patients.

From a business point of view, the precise identification of the major deficit and cost drivers in cancer care seems to be a reasonable first step. It provides the basis for developing appropriate strategies to finally solve the conflict between the demands for economic efficiency on the one hand and high quality of healthcare on the other hand. The aforesaid describes the constraints of the German healthcare system in general, but does this conflict between pressure through increasing treatment costs, insufficient reimbursement of highquality care by the Diagnosis-Related Group (DRG) billing system, and the demand to maintain high-quality care also exist for breast cancer care? And if so, is it a general problem in breast cancer care or is it particularly poignant for dedicated Breast Cancer Centers delivering the highest quality of care? In the past decades, there was a general trend to centralize and standardize cancer care, which also led the way in breast cancer care. This development was driven by the assumption that centralization and standardization of multidisciplinary care approaches like breast cancer treatment could increase quality of healthcare delivery and thereby potentially overall patient outcome (see also Lux et al. in this issue of Breast Care). A recent analysis of 3,940 patients suffering from invasive non-metastatic breast cancer explored the prognostic impact of being diagnosed and treated inside or outside of certified Breast Cancer Centers. Apart from common prognostic factors like age, disease stages and grading, being diagnosed and treated in certified Breast Cancer Centers turned out to be an independent prognostic factor with a hazard ratio of 0.7 [3]. The development and maintenance of these standardized and certified Breast Cancer Centers is time-consuming and costly. However, despite the emerging evidence of their positive impact on patient outcome, the additional efforts of running certified a Breast Cancer Center are not reimbursed by the DRG system.

To guarantee a high level of oncological care, guidelines for the diagnosis and treatment of different tumor types were developed [4]. Adherence to guideline is thus one of the accepted quality parameters of Breast Cancer Centers [5, 6]. The implementation of current guidelines and the addition of frequently emerging new standards and trends defined by revised guidelines into clinical routine of Cancer Centers is again time-consuming and requires additional financial resources [7]. As an alarming sign, the German hospital rating report 2011 showed clear signs of a financing shortfall. In their evaluation, Augurzky et al. [8] demonstrated a gap between costs and resources, which was threatening to trigger insolvency of every 10th hospital by 2010. Furthermore, with reference to the above-mentioned analysis, it was prognosticated that every 6th hospital will be threatened to fail economically by 2020 . Central measures for easing this tense situation are specialization, increased application of hospital IT solutions, improvement of management structures, and regional cooperation of hospitals [9]. According to Augurzky et al. [8], the average EBITDA Marge (Earnings before Interest, Taxes, Depreciation and Amortization) of all analyzed hospitals in Germany is at about $8 \%$. In general, at least $10 \%$ is considered to be necessary to sustain corporate value, but of all the analyzed clinics only $30 \%$ generate revenue of $\geq 10 \%$ EBITDA Marge. Further hampering or impairing structural and technical advancement, almost half of all investigated German hospitals do not generate sufficient revenue to finance their capital costs for investments [8]. These financial straits dominate the public healthcare sector. As a consequence, the cumulated gap of investments in Germany's healthcare sector with regard to the estimated required investment quota has reached $€ 30$ billion. This investment backlog might in particular impact the availability of new diagnostic and treatment measures for routine patient care and will provide ground for a subtle growth of inefficiency especially with regard to infrastructure. In this review, the economic constraints of breast cancer care in Breast Cancer Centers and potential measures to overcome these obstacles will be reviewed and discussed from a holistic business administration perspective.

\section{Health Care Has to Act Entrepreneurially}

With the introduction of DRGs, hospitals were forced to increase cost-effectiveness while maintaining performance 
quality. As a result of this increased economic pressure, the development of measures to increase process efficiency as a way of maintaining profitability has gained attention. Ahrens et al. [10], as a result of their analysis, suggested that hospitals should attempt to find additional sources of income outside the closed-end sectoral budgets of the public health insurance sector in Germany. In addition, to optimize their cost structure, applying standard optimization approaches to increase their ability to provide quality services at competitive costs would be another central pillar to cope with the financial challenges. Under DRG-based financing, hospitals basically receive a fixed payment rate for each case, which depends on a patient's diagnosis, performed procedures, and length of stay (when the predefined average maximum or minimum length of stay according to the DRG revenue definition is either exceeded or undercut). Of note, DRG-based financing disregards the level of care quality and specialization. As a consequence, particularly institutions offering a high level of care quality like Breast Cancer Centers, face increased pressure on their financial performance with a higher risk of insolvency, which forces them to optimize their DRG-based payment outcome. Depending on the hospitals individual performance spectrum, a high level of attraction is attached to patients with a low level of complexity and an expected short hospital stay (low-cost patients) or patients requiring complex procedures which trigger DRG revenue [11]. However, in turn, and this is a cause for concern, to treat morbid patients with a high level of complex diagnoses loses its attractiveness. As a consequence of the economic pressures put on the hospital sector, the DRG system seems in part to be the driving force to increase case volume and costs of health services on the payer's side. This rather general reflection can also be assigned to Breast Cancer Centers. Breast Cancer Centers seek to act more entrepreneurially as they attempt to grow their offered service portfolio to attract more patients, offer additional services partially for extra charges to the patient, and optimize their process efficiency and service orientation. This certainly can add value from the patients' point of view. However, as a potential drawback, some Breast Cancer Centers for the sake of cost optimization may be forced to shorten the length of inpatient stay or cut services due to economic constraints rather than medical needs.

\section{Business Competition - the Driving Force for Improvement? Integration of the Inpatient and Outpatient Sector}

Optimal integration and coordination of Breast Cancer Centers and outpatient healthcare providers is a prerequisite for the reorganization of the care structure for breast cancer patients. The main objective of integration is on the one hand the reduction of costs by streamlining the workflow processes between the inpatient and outpatient sector and on the other hand the reduction of losses by the reorganization and outsourcing of procedures which are not profitable for the inpatient care of a Breast Cancer Center based on the DRG reimbursement rate. Outsourcing of various treatments (e.g. for follow-up, preparation of medical treatments, individual health services in Germany ('IGel-Leistungen')) to already established peripheral outpatient care networks could result in a win-win situation since it might not just save the Breast Cancer Center resources but could increase the income of the outpatient sector which is refunded by EBM (Einheitlicher Bewertungsmaßstab). This in total could induce public welfare from an economic perspective. As a reasonable approach, Breast Cancer Centers with deficits should analyze their process costs to gain transparency on wins and losses in the whole patient treatment flow. Based on this holistic view they have to identify care procedures with deficit which can be outsourced without debilitating patient care quality and outcome (fig. 1). This collaboration and integration approach needs some kind of trans-sectoral quality and process management to be implemented to supervise workflows in order to harmonize and optimize the trans-sectoral treatment of patients. First steps into this direction were established by e.g. Disease Management Programs, integrated healthcare contracts, integrated palliative care programs, and medical care centers.

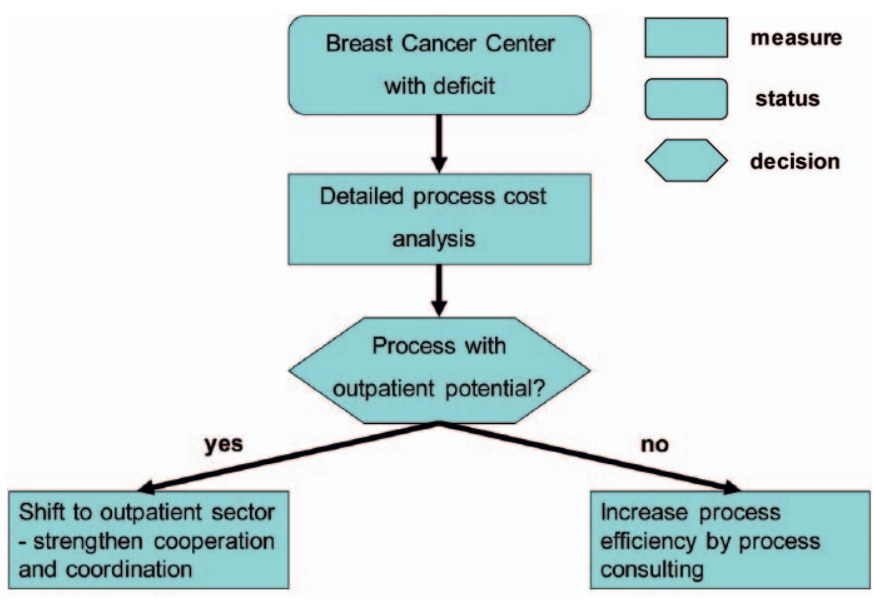

Fig. 1. Breast Cancer Center with deficit. To define measures to balance the budget, gaining transparency of gains and losses by a holistic process cost analysis is a reasonable first step. This provides the basis to decide about potential outsourcing of procedures or shortening of inpatient stay etc. Procedures with outpatient potential should be selected from both a business and, more importantly, a medical perspective. Shifting procedures out of the Breast Cancer Centers inpatient service requires optimal integration of the inpatient with the outpatient sector to avoid gaps in patient care. This strategy could reduce losses and increase patients satisfaction since it might allow several steps of treatment or follow-up to be done close to a patient's home. If procedures with insufficient DRG revenue cannot be outsourced, detailed process analysis and consulting to increase process efficiency and reduce losses could be considered. 
Growing Role of Comprehensive Management of Healthcare Information to Streamline Internal and Trans-Sectoral Workflow Processes

Predefined clinical pathways or workflows of diagnostic or treatment procedures were designed to simplify and harmonize the whole disease care pathway. By increasing the organizational level, care providers seek to reduce failure or error rates in this pathway on the one hand and increase its efficiency on the other. Thus, there is a permanent need to monitor the practicability of predefined clinical processes and workflows to streamline the complex multidisciplinary inpatient, outpatients, or - becoming assumedly more important in the future - trans-sectoral processes. This could potentially reduce the overall process costs for care providers but also the financial burden for the payers due to increased efficiency. To gain even more benefit of this potential approach, complete transparency and detailed knowledge of the involved process steps with respect to different revenues and costs are a prerequisite. Greiling and Quint [12] show various improvements by process modeling, and emphasize that in combination with process cost analysis, weaknesses and feasible solutions for improving quality and reducing costs in a clinical process can be identified. To streamline the data flow and communication of patient information from the inpatient to the outpatient sector, which is pivotal for increasing the level of integration of these care elements, comprehensive management of healthcare information has a central role. Today, IT technology is already capable of optimally supporting e.g. the accessibility of information for employees and patients or ease the ordering and coordination of resources and clinical services. Nowadays, increasing the compatibility of different healthcare IT solutions in the in- and outpatient sector, in various clinical in-house services remains a challenge. Improvements in this area harbor further potential for the increase of quality, saving of resources and time, as well as better utilization of clinical facilities. Data security must be guaranteed in the whole IT process.

\section{Quality}

In breast cancer care it is a common assumption that centralization and a coordinated multidisciplinary approach of breast cancer treatment lead to significant improvement in survival rates [13]. For instance, the 7-year survival of breast cancer patients improves depending on the volume of treated patients and on whether or not a patient is treated in a certified Breast Cancer Center. Conversely, being treated in smaller departments impacts negatively on patient survival $[14,15]$. In Germany, certified Breast Cancer Centers offer high-quality medical care, and a recent publication suggest an overall positive impact on survival when being treated in a Breast Cancer Center [7]. This substantiates the hypothesis that this effect is the result of quality-assured healthcare implemented and controlled by the certification process [3]. Landercasper and Tafra [16] identified in their work processes of care with either an inverse or a direct relationship between quality and cost. As a consequence, increasing quality could have a positive or negative impact on costs. Thus, a detailed analysis of processes by e.g. quality management could provide opportunities to concurrently lower cost and improve quality which in the end could also ameliorate the financial constraints of Breast Cancer Centers in Germany.

\section{Financial Aspects with Respect to DRG-Based Reimbursement}

A full cost accounting study investigated financial indicators of specific interventions related to breast cancer care based on data of the University Breast Center Franconia. As an outcome of this research, no general conclusion regarding the financial affordability of Breast Cancer Centers could be drawn. Depending on the complexity of the breast conserving surgical approach, DRG revenue ranges from $€ 1,691.53$ to $€ 4,160.19$, a difference of $€ 2,468.66$ per patient with an average revenue of $€ 3,659.49$. The average profit is $€ 958.52$, with average costs of $€ 2,700.97$ per patient. Inpatient partial excision as a contrary example results in a loss of $€ 162.70$ per patient. Not included in the full cost accounting by Wagner et al. [17] were expenses and revenues for studies, documentation for quality purposes, and private medical practice. Another notable cost trigger - necessary to guarantee high quality - is certification. For their initial certification, Breast Cancer Centers have to spend about $€ 237,303$ (for 4 years). This spending and additional costs in the subsequent years for quality assurance measures and recertification are not covered or reciprocally financed by DRG revenues. In a 440 patient cohort suffering from breast cancer, $66.8 \%$ answered the question 'Do you know what a certified center is?' with a 'Yes'; furthermore, only 33.2\% of 428 involved patients answered that certification was not a reason for their choice of hospital, all others said it was the main reason or 1 reason for their choice. A willingness-to-pay analysis (basic model microeconomics) estimated for mastology patients a willingness to pay $€ 643.65$ and for gynecological oncology patients $€ 563.59$ per service. Only $7.2 \%$ of all questioned patients rejected additional charges [18]. On the other hand, in 2006, deficits for primary breast cancer care of up to $€ 1,300$ were highlighted which require internal cross-subsidization by hospitals. The chairman of the health insurance company AOK North Rhine-Westphalia Jacobs emphasizes that 'money follows quality'; but often quality - especially in Breast Cancer Centers - is not getting paid as Beckmann et al. [19] explain. Full cost accounting shows that there is partial underfinancing of several treatments in a Breast Cancer Centre so that matching funding is necessary to provide and 
maintain a high level of quality. Breast Cancer Centers generate losses with some DRGs and gain profit with others. Therefore, process cost analysis seems to be particularly valuable for treatments that break even or with a large amount of treatments with high capital volume.

\section{Patient Satisfaction}

Quality and cost-efficiency are important determinants to manage a Breast Cancer Center. However, another crucial factor which increasingly has to be taken into account is patient satisfaction. Particularly breast cancer is an intimate diagnosis which affects the personality and integrity of the majority of breast cancer patients. Thus, as endorsed by the report of Hewitt et al. [20], psychosocial services can provide significant benefits in terms of quality of life and success in coping with this serious and life-threatening disease for patients and their families. The need for psycho-oncological support for patients is also supported by the work of Goldmann-Posch et al. [21]. Wiegard et al. [22] underline that health-related quality of live in relation to breast cancer treatment is determined essentially by a patient's psychological state. Not implemented in the previous definition of DRG-based reimbursement per case, an increasing amount of non-DRGrelevant costs arise for instance from ambulatory care, research and teaching, psychological, psychiatric and psychooncological care, as well as amortizations [23]. In principle, the need for a service portfolio of complementary and alternative medicine (CAM) is underscored by the study of Matsuno [24] on breast cancer survivors who reported that they perceived CAM therapies as helpful. However, this can hardly be implemented or has to be restricted in Breast Cancer Centers due to economic constraints. A 652 patient investigation on breast cancer patient satisfaction from certified Breast Cancer Centers and non-certified clinics reported generally a high level of satisfaction. Factors like psychological distress had a higher explanatory power on patient satisfaction then the place of treatment. Only for the assessment criterion 'overall judgment' a significant difference between certified Breast Cancer Centers (1.28) and noncertified clinics (1.19) $(\mathrm{p}=0.017)$ was noted [25]. 'Satisfied patients are more likely to return to a hospital if they need medical care' [26]. For this reason, high patient satisfaction in the long run leads to an economic and competitive advantage for healthcare providers, and provides the rationale to initiate an inside 'patient-centered' marketing strategy.

\section{Specialization}

There is growing evidence that treatment of breast cancer by a specialized and multidisciplinary team improves overall patient outcome. It is important to note that in the case of breast cancer care it is not only the breast surgeon's 'case load' which is relevant for the increase in quality and outcome but rather the 'case load' of all specialized experts involved in the diagnosis and treatment of breast cancer patients [27]. Porter and Guth [28] describe the existing German healthcare providers - divided into functions, specialization, and sites as a fragmented health providing system. Coordination and optimization of the whole treatment process is limited. Payment per performance and quality instead of just case volume as well as better coordination of services will increase quality. Higher specialization of services and transparency of result quality by appropriate and mandatory reporting will increase the competition between centers and make a change regarding these problems for health providers and healthcare in general [28].

\section{Breast Cancer Center - a Holistic Benchmark}

The current economic constraints in Breast Cancer Centers are ultimately caused by an insufficient coverage of costs for the highly specialized services provided and costs related to certification processes which are disregarded by the DRGbased reimbursement system. Options for ameliorating this obstacle are either to change the DRGs related to breast cancer care or to improve process efficiency and reduce carerelated costs. For this reason, a process-consulting approach was developed integrating the substantial experience of a hospital consulting team, of medical experts in oncology, guidelines, scientific literature, certification criteria, and best practice elements of several worldwide renowned cancer centers. A systematic analytic tool was designed (fig. 2), addressing 5 major categories: i) the complete clinical process of a breast cancer center, ii) communication, iii) center management, iv) infrastructure and v) strategy and research [29]. To our knowledge, this is the first and most comprehensive consulting approach to allow a structured and reproducible holistic analysis of Breast Cancer Centers. The approach is based on the capability maturity model integration which was initially developed to describe the maturity of industrial processes. During the assessment of a center, each of the more than 1,500 different criteria is reviewed in structured interviews with the different stakeholders of the Breast Cancer Center. Subsequent to the review phase, results are evaluated using a weighting matrix and reported as radial diagram presentations. This allows to clearly identify weaknesses and strength of an organization and to define opportunities for improvement. Besides cancer centers, this approach was developed for the treatment of stroke, acute coronary syndrome, heart failure, and radiology departments. The main aims of this best practice tool are to improve process quality and efficiency in the whole clinical process workflow, increase the level of integration of all stakeholders involved in inpatient and outpatient breast cancer care, and optimize center management 


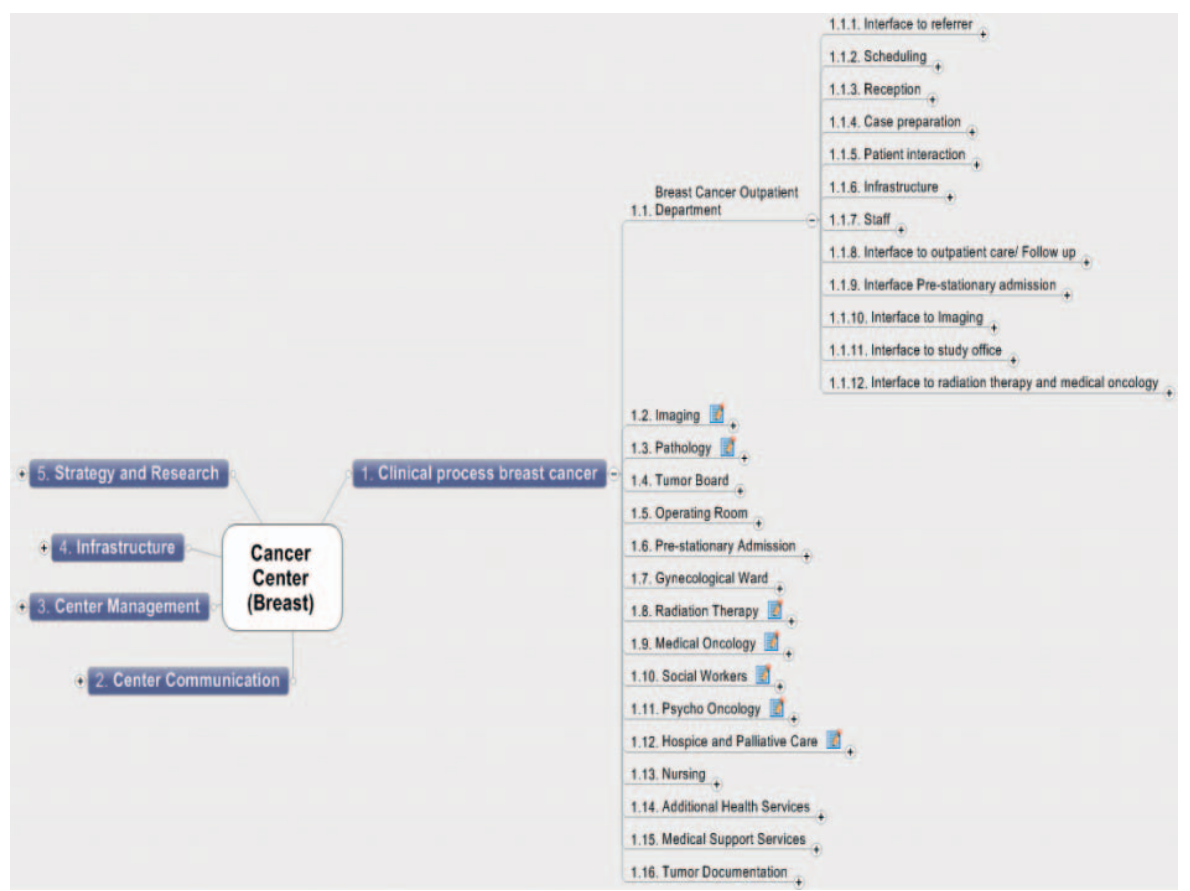

Fig. 2. Structured process maturity and efficiency assessment approach to improve process quality and efficiency. To improve process efficiency within a Breast Cancer Center, a holistic and systematic process assessment approach was developed which considers 5 major categories: clinical process (all aspects of breast cancer care), center communication, center management, infrastructure, and strategy and research. Based on the outcome of a systematic analysis (performed by structured interviews and visits of all stakeholders), measures can be developed to improve process quality and efficiency based on best practice elements implemented in the analysis tool. To illustrate this in depth assessment approach which considers the ultimate high complexity of breast cancer center, 2 sub-branches under the main category 'clinical process' are presented. The so-called capability maturity model integration (CMMI) has been modified and adapted to systematically analyze certified Breast Cancer Centers. This best practice model contains over 1,500 criteria for efficiency and quality beyond the 5 major categories [29]. and infrastructure as well as communication with a view to IT and information management. Based on its unique nature, the model is able to increase the level of predictability in replicating high-quality medical care. This analytic approach particularly considers the complexity of breast cancer care owing to the interdisciplinarity of a Breast Cancer Center, which is fundamental for achieving higher quality of care and better outcome, and could also improve patient satisfaction. As a combined effect, this structured optimization approach could potentially also result in economic benefits.

\section{Summary and Future Prospects}

Recent data suggest that the high level of quality and standardization in Breast Cancer Centers contributed - besides other improvements in medical diagnostics and treatment - to the decline of the overall breast cancer-related mortality. However, this high level of care quality increases costs for the centers, which are not covered by the current DRG-based reimbursement system in Germany. Several approaches to these financial constraints can be discussed. To reduce the Breast Cancer Centers financial losses while maintaining patient care quality, outsourcing of specific non-profitable treatments to the outpatient sector while optimizing and strengthening cooperation between inpatient and outpatient healthcare services and improving the integration of care elements seems a promising approach. Managing and monitoring of this trans-sectoral care system could improve quality and harmonize the trans-sectoral workflow. This will in addition result in a better outreach of centers to peripheral healthcare providers, which might improve follow-up and allow care of patients close to their homes. A potential role to support the transition of procedures from the inpatient to the outpatient sector can be attributed to different solutions in healthcare IT. Their use will allow sufficient information exchange and promote the level of integration of the inpatient and outpatient sector. Healthcare consulting services can be of help by using specific analysis approaches to detect gains and losses in a center's procedures and provide transparency of the actual cost situation to the C-level management. Based on this information, measures can be developed to improve revenues by improving care quality and, even more importantly, care efficiency. Ultimately, in order to preserve the achievements in care quality in Breast Cancer Centers, it is a political task to define new DRGs which appreciate and fully cover the significant amount of extra spending to achieve and maintain high quality of breast cancer care.

\section{Disclosure Statement}

Rene Seidel is employed at Siemens AG, Healthcare Sector, Erlangen, Germany. Josef Hoellthaler is employed at Siemens AG, Healthcare Sector, Erlangen, Germany. Wieland Voigt is Associate Professor at the University of Halle/Saale Germany and employed at Siemens AG, Healthcare Sector, Erlangen Germany. There is no additional conflict of interest for any of the authors. 


\section{References}

1 Statistisches Bundesamt: Gesundheit. Krankheitskosten. Fachserie 12, 2010, Reihe 7.2, pp. 1-45.

2 Statistisches Bundesamt: Statistisches Jahrbuch - Deutschland und Internationales. Gesundheit 2012;4:115-151.

3 Beckmann MW, Brucker C, Hanf V, et al.: Quality assured health care in certified breast centers and improvement of the prognosis of breast cancer patients. Onkologie 2011;34:362-367.

4 Kreienberg R: Interdisziplinäre S3-Leitlinie für die Diagnostik, Therapie und Nachsorge des Mammakarzinoms Leitlinie (Langversion). Germering/ München, Zuckschwerdt, 2012.

5 Barni S, Venturini M, Molino A, et al.: Importance of adherence to guidelines in breast cancer clinical practice. The Italian experience (AIOM). Tumori 2011;97:559-563.

6 Schwentner L, Wolters R, Wischnewsky M, et al.: Survival of patients with bilateral versus unilateral breast cancer and impact of guideline adherent adjuvant treatment: a multi-centre cohort study of 5,292 patients. Breast 2012;21:171-177.

7 Beckmann MW, Adler G, Albers P, et al.: Onkologie Dreistufenmodell optimiert Behandlung unter Kostendeckung. Wie die künftigen Strukturen der onkologischen Versorgung in Deutschland aussehen sollten. Dtsch Ärztebl International 2007; 104:3004.

8 Augurzky B, Gülker R, Krolop S, et al.: Krankenhaus Rating Report 2011. Die fetten Jahre sind vorbei. Executive Summary; in RWI Materialien, Heft 67, Essen, RWI, 2011.

9 Krolop S: Krankenhausversorgung am Wendepunkt. Accenture 2012; pp 1-2.

10 Ahrens U, Bocking W, Kirch W: (DRG introduction in Germany. Options for action of hospitals). Med Klin 2005;100:26-31.

11 Herwartz H, Strumann C: On the effect of prospective payment on local hospital competition in Germany. Health Care Manag Sci 2012;15:48-62.
Greiling M, Quint U: (Clinical pathways from an economic viewpoint). Orthopade 2010;39:752-757.

13 Roohan PJ, Bickell NA, Baptiste MS, et al.: Hospital volume differences and five-year survival from breast cancer. Am J Public Health 1998;88:454457.

14 Oberaigner W, Stuhlinger W: Influence of department volume on cancer survival for gynaecological cancers - a population-based study in Tyrol, Austria. Gynecol Oncol 2006;103:527-534.

15 Beckmann MW, Bani MR, Loehberg CR, et al.: Are certified breast centers cost-effective? Breast Care (Basel) 2009;4:245-250.

16 Landercasper J, Tafra L: The relationship between quality and cost during the perioperative breast cancer episode of care. Breast 2010;19:289-296.

17 Wagner S, Bani M, Fasching P, et al.: Ist ein Brustzentrum finanzierbar? Berechnung einzelner Leistungen am Beispiel des Universitäts-Brustzentrums Franken (UBF). Geburtsh Frauenheilk Geburtshilfe und Frauenheilkunde 2008;68:1178-1183.

18 Thiel FC, Scharl A, Hildebrandt T, et al.: Financing of certified centers: a willingness-to-pay analysis. Arch Gynecol Obstet 2012;Epup ahead of print.

19 Beckmann MW, Kaufmann M: Ist die Versorgung von Patientinnen mit Mammakarzinom im derzeitigen Vergütungssystem finanzierbar - Wird Qualität auch bezahlt in Brustzentren? Geburtshilfe und Frauenheilkunde 2007;67:957-958.

20 Hewitt M, Herdman R, Holland J, Council NR (eds): Meeting Psychosocial Needs of Women with Breast Cancer. Washington, National Academies Press, 2004.

21 Goldmann-Posch U, Martin RR: Über-Lebensbuch Brustkrebs: Die Anleitung zur aktiven Patientin - In Abstimmung mit international anerkannten Brustkrebs-Experten. Stuttgart, Schattauer GmbH, 2012.
22 Wiegard K, Albert U-S, Zemlin C, et al.: Psychische Belastung von Brustkrebspatientinnen: Screening und psychoonkologischer Unterstützungswunsch als Indikatoren der Lebensqualität. Senologie 2012;9:173-179.

23 Vogl M: Assessing DRG cost accounting with respect to resource allocation and tariff calculation: the case of Germany. Health Econ Rev 2012;2:15.

24 Matsuno RK, Pagano IS, Maskarinec G, et al.: Complementary and alternative medicine use and breast cancer prognosis: a pooled analysis of four population-based studies of breast cancer survivors. J Womens Health (Larchmt) 2012;21:12521258.

25 Weissflog G, Gotze H, Klinitzke G, et al.: (Better patient orientation through certified cancer centres in oncological care? Patient satisfaction in breast cancer patients in certified breast cancer centres and noncertified hospitals). Z Psychosom Med Psychother 2011;57:343-355.

26 Rave N, Geyer M, Reeder B, et al.: Radical systems change. Innovative strategies to improve patient satisfaction. J Ambul Care Manage 2003; 26:159-174.

27 Wallwiener D, Brucker SY: Zertifizierte multidisziplinäre Brustzentren: Ein Implementierungsprojekt der Deutschen Krebsgesellschaft und der Deutschen Gesellschaft für Senologie in Partnerschaft mit der Deutschen Gesellschaft für Gynäkologie und Geburtshilfe. Senologie 2011;8:92-95.

28 Porter ME, Guth C: Chancen für das deutsche Gesundheitssystem von Partikularinteressen zu mehr Patientennutzen. Berlin, Springer/Gabler, 2012.

29 Hopmeier T, Lux MP, Hoellthaler J, et al.: Können Organkrebszentren und Onkologische Zentren die Versorgungsqualität optimieren und gleichzeitig ökonomischer arbeiten? - Ein Best Practice Modell für die Entwicklung Onkologischer Exzellenzzentren. Senologie 2012;9:A70. 